\title{
Galectin-3 is induced in rheumatoid arthritis synovial fibroblasts after adhesion to cartilage oligomeric matrix protein
}

\author{
M Neidhart, F Zaucke, R von Knoch, A Jüngel, B A Michel, R E Gay, S Gay
}

Ann Rheum Dis 2005;64:419-424. doi: 10.1136/ard.2004.023135

See end of article for authors' affiliations

Correspondence to

Correspondence to:
Dr M Neidhart, Centre for Experimental Rheumatology, University Hospital, Gloriastrasse 25, CH8091 Zurich, Switzerland; michel.neidhart@usz.ch

Accepted 20 June 2004 Published Online First 2 September 2004

\begin{abstract}
Background: Galectin-3 is expressed in the synovial tissue of patients with rheumatoid arthritis (RA), particularly at sites of joint destruction.

Objective: To explore the possibilities that galectin-3 is induced either by proinflammatory cytokines or by adhesion to cartilage components.

Methods: Cell culture plates were coated with fibronectin, collagens I-VI, or cartilage oligomeric matrix protein (COMP), and the suspended cells were then added. The medium was changed after 1 hour at $37^{\circ} \mathrm{C}$. Adherent cells were further incubated for 18 hours in the presence or absence of tumour necrosis factor $\alpha$ (TNF $\alpha$ ) or interleukin 1 $\beta$. Cells were pretreated with murine lgG1, anti-CD29, -CD51, -CD61 (integrins), or -CD3 monoclonal antibodies and transferred to culture plates coated with COMP. Adherent cells were counted by light microscopy. The expression of intracellular galectin-3, or cell surface CD29, CD51, and CD61 was determined by flow cytometry before and after adhesion.

Results: Four times more RA synovial fibroblasts (SF) than osteoarthritis SF adhered to COMP. RA SF presented more cell surface integrins, and monoclonal antibodies against CD51 inhibited the adhesion to COMP by $80 \%$. TNF $\alpha$ reduced the expression of CD61 and the adhesion to COMP, but did not reverse the adhesion once it had taken place. The adhesion of RA SF to COMP was found to increase the intracellular level of galectin-3. In contrast, intracellular galectin-3 decreased after exposure to TNF $\alpha$.

Conclusion: The increase of galectin-3 occurs after adhesion to COMP, and the $\alpha \vee \beta 3$ receptor (CD51) CD61) has a pivotal role in this process.
\end{abstract}

$\mathrm{R}$ heumatoid arthritis (RA) is a chronic inflammatory disease that is characterised by inflammation and progressive destruction of the affected joints. Galectins participate in cellular homoeostasis. Both intracellular and extracellular activities of galectins have been described, with the former typically independent of lectin activity. ${ }^{2}$ Increased expression of galectin- 3 has been associated with the development of tumours and inflammation. ${ }^{3}$ Intracellularly, galectin-3 has been shown to be an inhibitor of apoptosis. ${ }^{2}$ Expression of galectin-3 has been reported in the synovial tissue of patients with RA, including at sites of joint destruction. ${ }^{4}$ Very little information is available about specific factors triggering the expression of galectin-3, with the exception that the promoter region contains a serumresponsible element. ${ }^{5}$ Proinflammatory cytokines did not stimulate the expression of galectin-3 mRNA in vitro. ${ }^{4}$ Therefore, we aimed at investigating whether the increase of galectin-3 in synovial fibroblasts (SF) occurs after these cells adhere to specific components of the extracellular matrix (ECM).

Integrins mediate the attachment of RA SF to fibronectinrich sites of cartilage. ${ }^{6}$ We analysed, in addition to fibronectin, the adhesion of SF to collagens and cartilage oligomeric matrix protein (COMP). COMP is a component of the hyaline cartilage and is produced by chondrocytes and SF. ${ }^{7}$ COMP fragments are markers of joint destruction, ${ }^{89}$ synovial activation, ${ }^{7}$ and are involved in autoimmune phenomena. ${ }^{10}{ }^{11}$

Integrins are a family of proteins that can mediate both intercellular adhesion and cell adherence to the ECM. They are composed of a larger $\alpha$ subunit and a smaller $\beta$ subunit. The increased expression of integrins on the surface of RA SF has been associated with their enhanced binding to the ECM. ${ }^{12}$ Previous functional data support the concept that signalling events mediated by integrin contribute to the invasive nature of RA SF. ${ }^{13}$ Here we show that the up regulation of galectin-3 in RA SF occurs after cell adhesion to COMP through a mechanism dependent on integrin.

\section{PATIENTS AND METHODS}

\section{Patients}

Synovial tissue specimens were obtained during joint arthroplasty from nine patients with RA and four patients with osteoarthritis (OA). All patients with RA and OA fulfilled the respective criteria of the American College of Rheumatology. ${ }^{14}{ }^{15}$ In contrast with RA tissues, OA tissues, and normal samples had no lining cell hyperplasia and no subintimal cellular infiltration. The study was approved by the ethical committee of our institution (University Hospital Zurich)

\section{Cell culture}

Tissue specimens were washed with phosphate buffered saline (PBS), minced, and digested enzymatically with $1.5 \mu \mathrm{g} / \mathrm{ml}$ Dispase II (Roche). The released cells were grown for 4-8 passages in Dulbecco's modified Eagle's medium (DMEM) supplemented with fetal calf serum (FCS), $50 \mathrm{IU} /$ $\mathrm{ml}$ penicillin, $50 \mu \mathrm{g} / \mathrm{ml}$ streptomycin, $2 \mathrm{mM}$ L-glutamine, $0.5 \mu \mathrm{g} / \mathrm{ml}$ amphotericin $\mathrm{B}$, and $10 \mathrm{mM}$ HEPES (Life

Abbreviations: $B S A$, bovine serum albumin; $C D 29$, integrin $\beta 1 ; C D 51$, integrin $\alpha \mathrm{V} ; \mathrm{CD} 61$, integrin $\beta 3$; COMP, cartilage oligomeric matrix protein; DMEM, Dulbecco's modified Eagle's medium; ECM, extracellular matrix; ELISA, enzyme linked immunosorbent assay; FACS, fluorescence activated cell sorting; FCS, fetal calf serum; FLI, fluorescence index; IL1 $\beta$, interleukin 1 $\beta$; OA, osteoarthritis; PBS, phosphate buffered saline; $\mathrm{PE}$, phycoerythrin; RA, rheumatoid arthritis; SF, synovial fibroblasts; TNF $\alpha$, tumour necrosis factor $\alpha$; TSP-1, thrombospondin-1 
Technologies). One week before the start of the experiments the cells were cultured in either DMEM containing 10\% FCS or were serum starved in medium containing $0.5 \%$ FCS. Flow cytometric analysis (below) confirmed that after four passages more than $98 \%$ of the cells were fibroblasts.

\section{Cytokines}

RA SF and OA SF cultured in DMEM containing $10 \%$ or $0.5 \%$ FCS were incubated for 18 hours at $37^{\circ} \mathrm{C}$ with $10 \mathrm{ng} / \mathrm{ml}$ endotoxin-free recombinant human tumour necrosis factor $\alpha$ $(\mathrm{TNF} \alpha)$ or $1 \mathrm{ng} / \mathrm{ml}$ interleukin $1 \beta$ (ILl $\beta$ ) (Invitrogen). These concentrations were chosen, because they correspond to "physiological" levels, as can be measured in RA synovial fluid. In the case of TNF $\alpha$, a higher dose (for example, $100 \mathrm{ng} / \mathrm{ml}$ ) would increase the risk that the cells undergo apoptosis.

\section{Adhesion assays}

Serum starved SF cultures were used. Cell culture plates were coated with $100 \mathrm{ng} / \mathrm{ml}$ of purified human fibronectin (BD Biosciences), collagens type I-VI (Centre for Experimental Rheumatology, Zurich), or COMP (Centre for Biochemistry, Cologne). Unreduced proteins were used for coating. Fibronectin and COMP were diluted in PBS, while collagens were diluted in $0.5 \mathrm{M}$ acetic acid. After incubating the plates at $4^{\circ} \mathrm{C}$ for 24 hours, they were washed three times with PBS. The plates were blocked with $10 \mu \mathrm{g} / \mathrm{ml}$ heat denatured bovine serum albumin (BSA; Sigma, treated for 15 minutes at $\left.85^{\circ} \mathrm{C}\right) .{ }^{16}$ After an incubation for 1 hour at $37^{\circ} \mathrm{C}$, the plates were washed with FCS-free DMEM.

RA SF and OA SF were detached using collagenases (Accutase, Omnilab), washed, suspended in FCS-free DMEM, and incubated for 30 minutes at $37^{\circ} \mathrm{C}$ in a tube rotator. The cells were then added to the coated culture plates $\left(2 \times 10^{5}\right.$ cells/well) in FCS-free DMEM containing 0-100 ng/ $\mathrm{ml} \mathrm{TNF} \alpha$, and incubated at $37^{\circ} \mathrm{C}$. The medium was changed (using DMEM containing $0.5 \%$ FCS) after 1 hour and the remaining adherent cells were incubated for an additional 18 hours at $37^{\circ} \mathrm{C}$. A light microscope was used, by two independent observers, to count the cells at two times: 30 minutes after changing the medium (total incubation time 1.5 hours) and at the end of the incubation period. After the 18 hour incubation period the intracellular level of galectin-3 protein was determined by fluorescence activated cell sorting (FACS) and the level of galectin-3 in the cell supernatant was measured by enzyme linked immunosorbent assay (ELISA).

\section{Blocking experiments}

Serum starved SF cultures were used to explore the mechanisms underlying the adhesion of RA SF to COMP. RA SF and OA SF were pretreated with $1 \mu \mathrm{g} / \mathrm{ml}$ murine IgGl (as negative control) or monoclonal antibodies against human CD29, CD51, CD61, or CD3 (BD Transduction Laboratory). Culture plates were coated with $100 \mathrm{ng} / \mathrm{ml}$ COMP and blocked with heat denatured BSA. Cells were treated with collagenases (Accutase), washed, and suspended in FCS-free medium. The cells were then pretreated with monoclonal antibodies, as described above, for 10 minutes at $22-24^{\circ} \mathrm{C}$ in a tube rotator. The pretreated cells were transferred to the coated culture plates and incubated for 1 hour at $37^{\circ} \mathrm{C}$. The culture medium was changed and the adherent cells were incubated for an additional 30 minutes (total 1.5 hours), then counted by two independent observers using a light microscope.

\section{TNF $\alpha$ and integrin expression}

A final experiment was carried out to determine if the expression of CD29, CD51, and CD61 changed in the presence

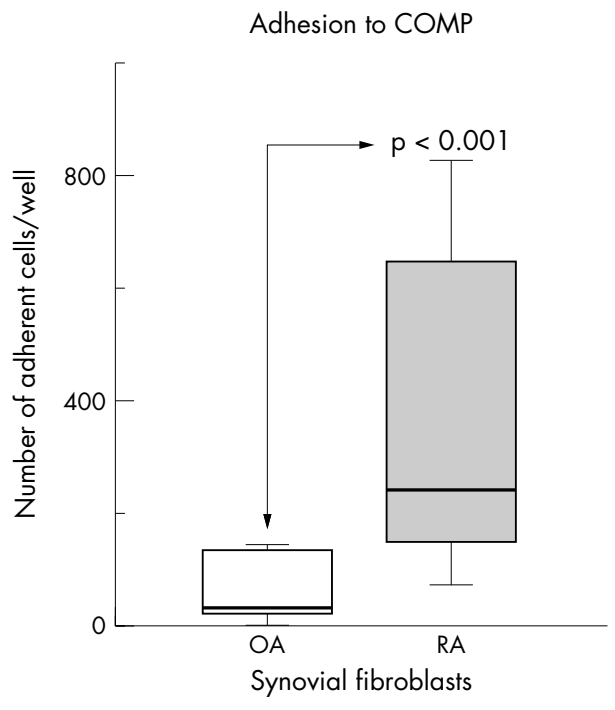

Figure 1 Number of SF from patients with OA or RA adhering to plates coated with COMP. Four times more RA SF than OA SF adhered to COMP.

TNF $\alpha$. Serum starved RA SF and OA SF cultures were treated with collagenases (Accutase), washed, and suspended in FCS-free medium. The expression of CD29, CD51, and CD61 on both cell types was measured by FACS. The cells were then incubated for 30 minutes at $37^{\circ} \mathrm{C}$ in medium containing 0 or $100 \mathrm{ng} / \mathrm{ml} \mathrm{TNF} \alpha$.

\section{Flow cytometry}

Before staining, single cell suspensions were obtained by treating cultures with collagenases (Accutase). The cells were resuspended in DMEM with $0.5 \%$ FCS, then incubated for 20 minutes at $37^{\circ} \mathrm{C}$ in a tube rotator. Control analysis was performed using fluorescein isothiocyanate conjugated antifibroblast monoclonal antibodies Thy-1 (clone AS02, Dianova) and anti-CD45 HLe-1 (Becton Dickinson) to confirm that after four passages more than $98 \%$ of the cells were fibroblasts, and to exclude the presence of contamination by a small population of monocytes that would influence

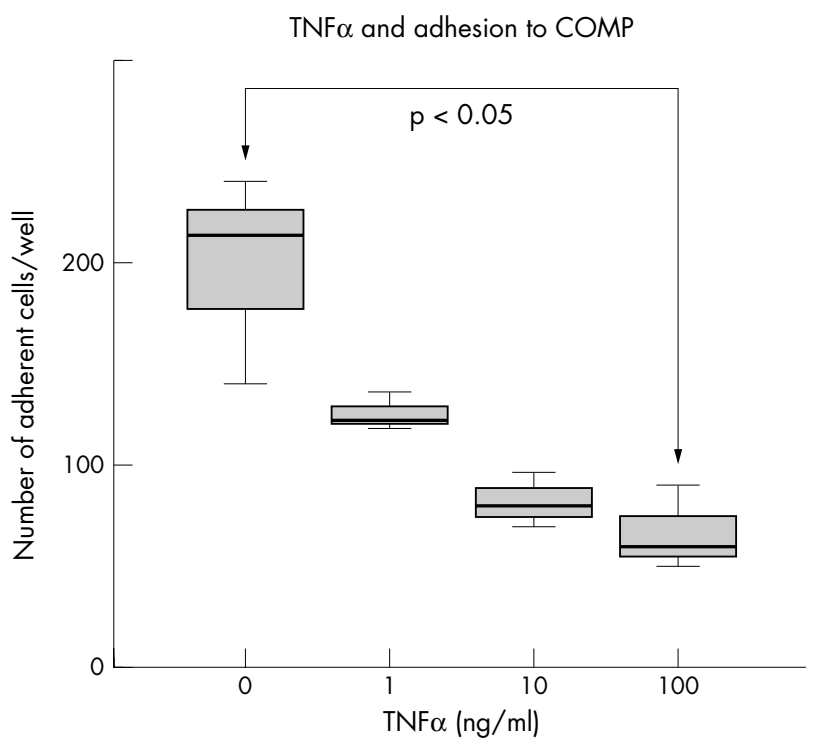

Figure 2 Number of RA SF adhering to plates coated with COMP, and dose dependent decrease of adhesion induced by TNF $\alpha$. 
the results. Gating was set on single cells, without debris or large cell aggregates.

Expression of CD51, CD61, and CD29 on the cell surface was detected indirectly by purified monoclonal antibodies (IgGl, BD Transduction Laboratory) and a phycoerythrin (PE) conjugated rat anti-murine IgGl (BD Biosciences). PE conjugated murine IgGl alone and PE conjugated CD45 HLe-1 monoclonal antibodies were used as negative controls. The fluorescence positive marker was set at $<2 \%$ using the negative control antibodies.

The intracellular level of galectin-3 protein in collagenasetreated and permeabilised cells (with BD permeabilising solution) was determined by FACS using PE conjugated murine monoclonal anti-galectin-3 antibodies (BD Biosciences). PE conjugated murine IgGl served as the negative control.

\section{ELISA}

The levels of galectin-3 were measured by an ELISA in cell culture supernatant using a previously described protocol. ${ }^{4}$ Briefly, plates were coated with affinity purified goat antigalectin-3 antibodies. Samples were added to the wells for 2 hours at $37^{\circ} \mathrm{C}$, followed by the addition of affinity purified rabbit anti-galectin-3 antibodies and a further incubation for 1 hour. After washing, goat antirabbit IgG horseradish peroxidase was added and incubated for 1 hour. Tetramethylbenzidine containing $0.001 \%$ hydrogen peroxide was used as substrate and the optical density was read at $450 \mathrm{~nm}$.

\section{Statistics}

The following equations were used for analysis:

Fluorescence index $(\mathrm{FLI})=\%$ positive cells $\times$ mean fluorescence of positive cells

FLI $\%=$ FLI of the given culture $\times 100 /$ FLI obtained by cells cultivated in $0.5 \%$ FCS

$\Delta \mathrm{FLI} \%=\mathrm{FLI} \%$ after $-\mathrm{FLI} \%$ before adhesion.

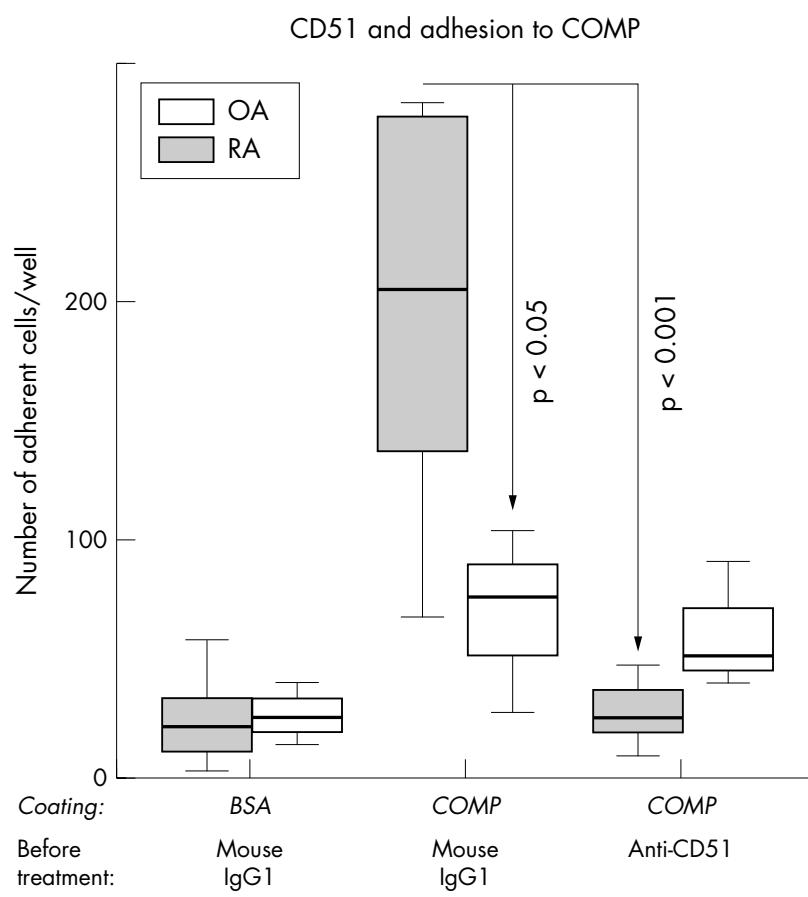

Figure 3 Number of SF from patients with RA or OA adhering to plates coated with COMP, and inhibition of adhesion by pretreatment with anti-CD51 monoclonal antibodies.

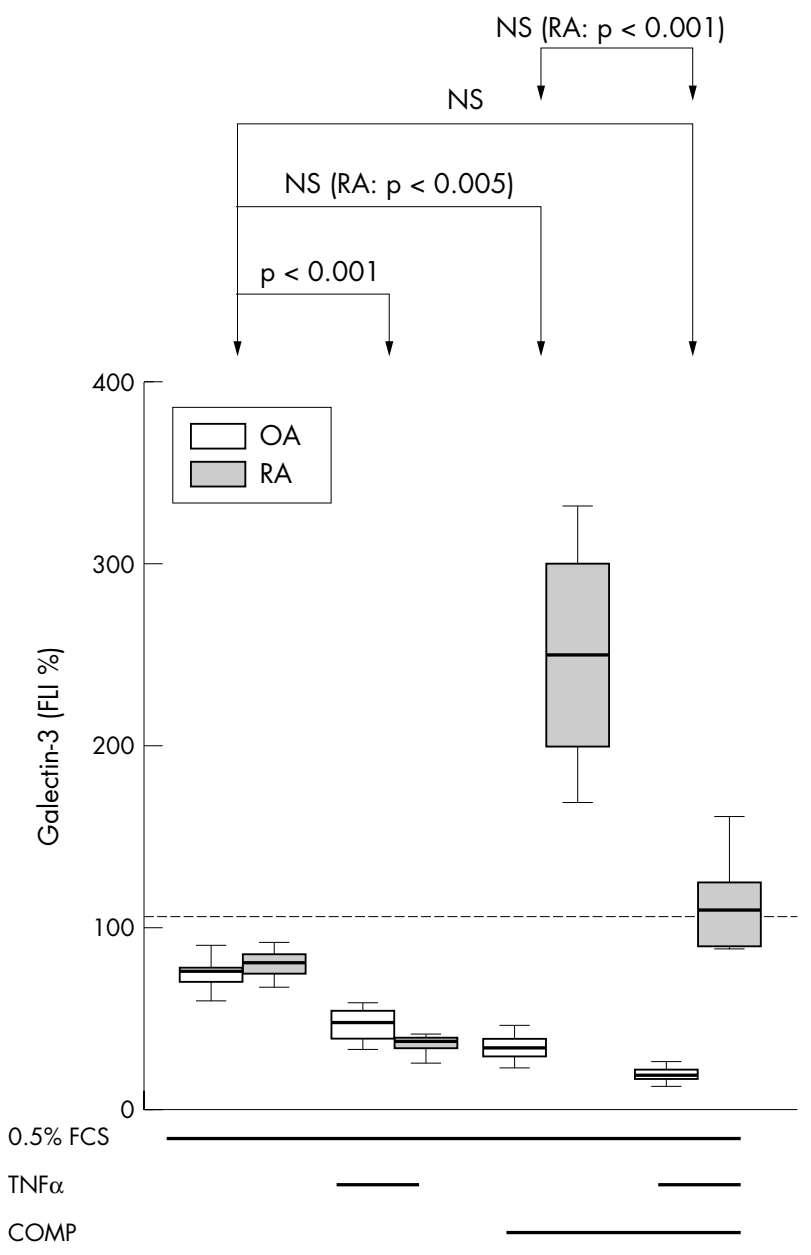

Figure 4 Galectin-3 in SF obtained from patients with OA or RA upon adhesion to culture plates coated with or without COMP, in the presence or absence of TNF $\alpha$. The binding assay was performed in cells adapted to $0.5 \%$ FCS. Galectin-3 was highly significantly increased in RA SF.

For statistical interpretation, the Mann-Whitney U test and Spearman's rank correlation test were used.

\section{RESULTS}

\section{Adhesion to COMP}

Figure 1 shows the significant results of the first adhesion assay. In the absence of TNF $\alpha$ in the culture medium, four times more RA SF than OA SF adhered to COMP $(\mathrm{p}<0.001$, $\mathrm{n}=8 \mathrm{RA}$ SF and $\mathrm{n}=3 \mathrm{OA} \mathrm{SF}$ ). For RA SF, this corresponds to $39(18) \%$ of the maximum adhesion obtained in culture plates coated with fibronectin, blocked with heat denatured BSA, and incubated in TNF $\alpha$-free medium. The number of cells per well counted after a total incubation time of 1.5 hours was equal to the number at the conclusion of the 18 hour incubation period. The number of adherent cells/well not coated with COMP (negative control) was $<20$ and subtracted from the result. The intraindividual coefficient of variation in the adhesion assay was $7 \%$.

Figure 2 demonstrates that when simultaneously adding RA SF with varying doses of TNF $\alpha$ to culture plates coated with COMP, there is a dose dependent reduction in the number of cells adhering to COMP, reaching $78 \%$ inhibition $(\mathrm{p}<0.05, \mathrm{n}=3)$. When the culture medium is substituted I hour after cell adhesion to COMP with fresh medium containing 10 or $100 \mathrm{ng} / \mathrm{ml} \mathrm{TNF} \alpha$, the number of adherent cells counted 18 hours later remained the same. 


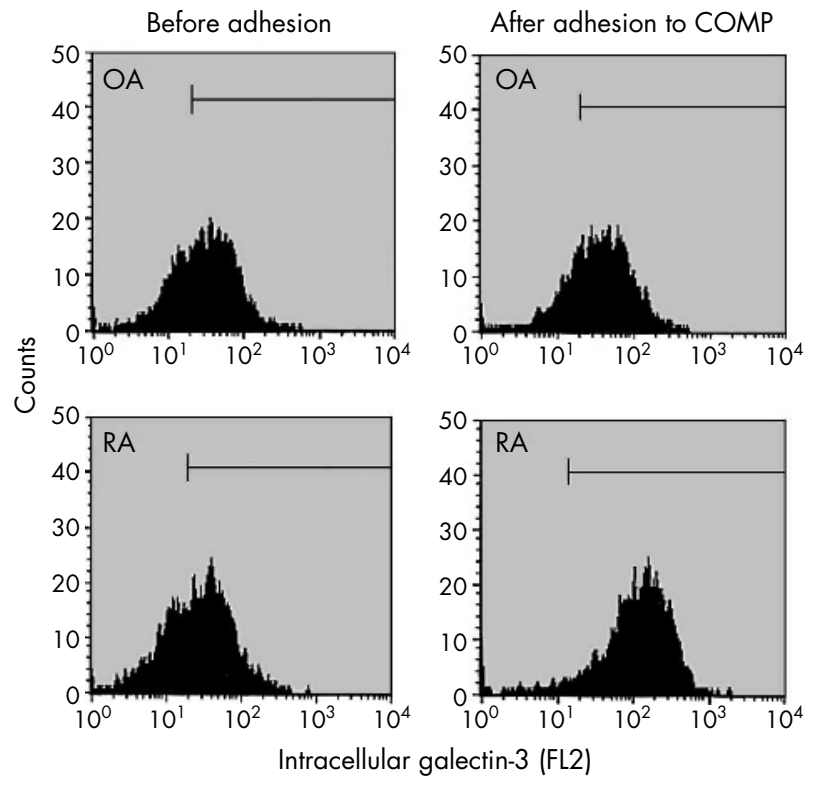

Figure 5 Galectin-3 in SF obtained from patients with OA or RA upon adhesion to culture plates coated with or without COMP. The line represents the $1 \%$ marker of negative lgG controls. Galectin-3 was induced in RA SF, but not in OA SF.

Inhibition of the adhesion to COMP by blocking CD5 1 Figure 3 shows that monoclonal antibodies against CD51 significantly blocked the adhesion of RA SF to COMP by at least $80 \%(p<0.001, n=6$ RA SF $)$. In a second set of experiments, pretreatment of RA SF with anti-CD29 or anti-CD61 monoclonal antibodies was less efficient than anti-CD51. Pretreatment with murine IgGl or anti-CD3 monoclonal antibodies had no effect on RA SF adhesion to COMP (data not shown).

\section{Modulation of galectin-3 by ECM components}

Figures 4 and 5 present the changes in the intracellular expression of galectin-3 protein in RA SF $(n=5)$ and OA SF $(\mathrm{n}=3)$, under normal culture conditions, after l week of serum starvation and 18 hours after cell adhesion to COMP, all in the presence or absence of $10 \mathrm{ng} / \mathrm{ml} \mathrm{TNF} \alpha$. The FACS results are presented as the mean (SD) change in FLI\%.

There was a distinct contrast in the change of intracellular galectin-3 expression between RA SF and OA SF upon cell adhesion to collagen type VI (data not shown) or more obviously COMP (figs 4 and 5). The adhesion of RA SF to COMP induced a significant increase in the expression of intracellular galectin-3 (255 (67)\%, p<0.005). This experiment was repeated with SF samples from two additional patients (one OA and one RA) in order to confirm this finding. Figure 5 shows representative examples of the FACS analysis (intracellular galectin-3) before and after RA SF and OA SF adhesion to COMP. No significant change of galectin-3 in the cell culture supernatant was detected after attachment to COMP (data not shown). In contrast with the response to collagen type VI and COMP, the expression of galectin-3 decreased after cell adhesion to fibronectin and collagen type III (data not shown).

Figure 6 shows that in both OA SF and RA SF serum starvation and $\mathrm{TNF} \alpha$ decreased the intracellular level of galectin-3 by $20-50 \%(p<0.005)$. However, serum starvation does not affect the level of galectin- 3 in the presence of TNF $\alpha$.

There was no change in galectin-3 expression when either RA SF or OA SF were transferred to fresh culture medium

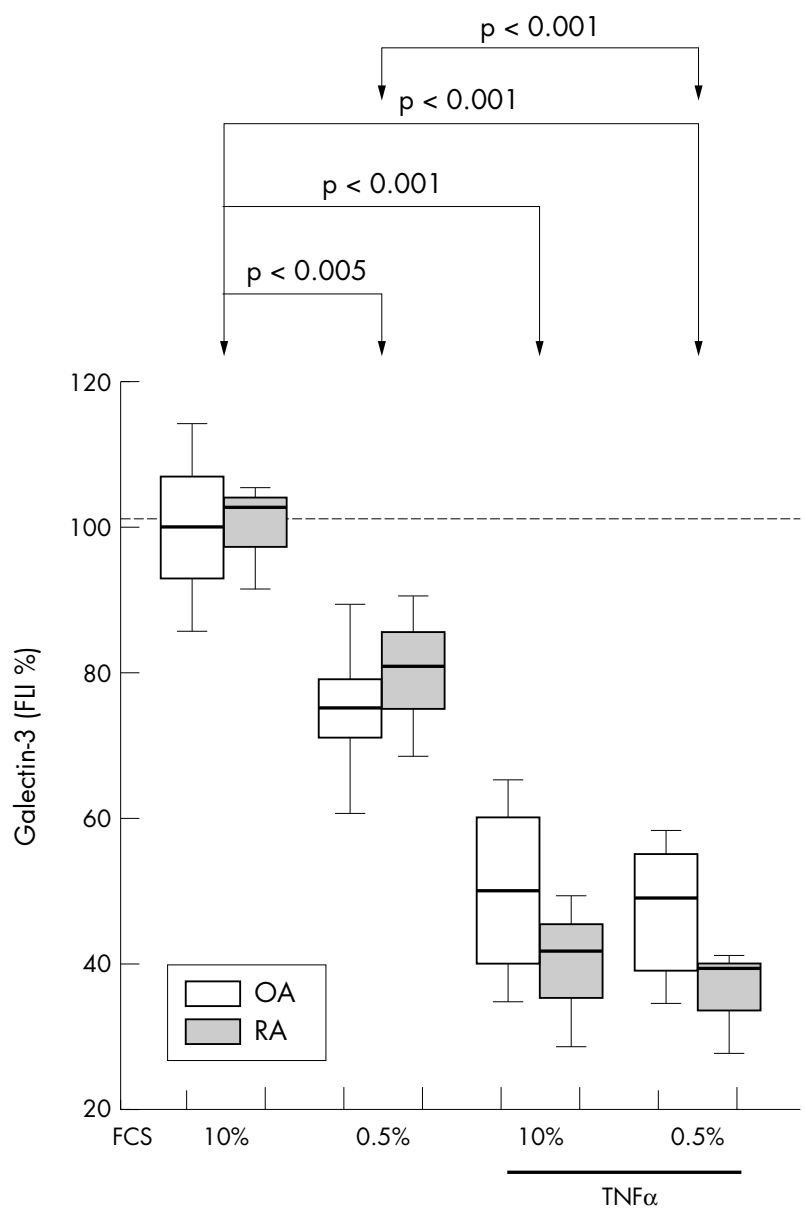

Figure 6 Galectin-3 in SF obtained from patients with OA or RA upon adhesion to culture plates. Differences between cell cultures maintained in 10 and $0.5 \% \mathrm{FCS}$ and effect of $10 \mathrm{ng} / \mathrm{ml} \mathrm{TNF} \alpha$ during the adhesion assay. Serum starvation and TNF $\alpha$ decreased the expression of galectin-3.

simultaneously with IL1 $\beta$, or after cell adhesion to collagens type I, II, IV, and V.

\section{Decrease of CD61 expression by TNF $\alpha$}

The expression of CD51, CD29, and CD61 on RA SF and OA SF was measured before and after a 30 minute incubation with $10 \mathrm{ng} / \mathrm{ml} \mathrm{TNF} \alpha$ (data not shown).

For OA SF, CD29 and CD51 were undetectable before stimulation in two of the three fibroblast cultures. In the positive OA cell culture (one of three), the 30 minute incubation with $\mathrm{TNF} \alpha$ slightly increased the expression of CD51 by $20-24 \%$. In all three OA cultures TNF $\alpha$ increased CD29 expression by 1.5- to 3-fold (as shown by the mean fluorescence intensity or the FLI).

RA SF expressed more cell surface integrins than OA SF. In RA SF, both CD51 and CD29 increased (two- to threefold) further upon stimulation with TNF $\alpha$. The most important finding, which provides an explanation for the results of the adhesion assays above, is the inhibition of the expression of CD61 during the short incubation with TNF $\alpha$. Both OA SF and RA SF showed a strong down regulation (by $37-98 \%$ and $29-61 \%$, respectively) of CD61.

\section{DISCUSSION}

In RA, about $39 \%$ of SF adhered to COMP, four times more than in OA, indicating that a specific receptor-ligand interaction may occur in RA. COMP is an important 
component of human hyaline cartilage. ${ }^{7}$ The adhesion of RA SF to COMP is reduced by a pretreatment with TNF $\alpha$. It can be argued that TNF $\alpha$ induced cell death and therefore reduced the number of adherent cells. However, the concentration used in those experiments was low and should not induce apoptosis in such a short time. The number of adherent cells after 1 and 18 hour incubation periods did not differ significantly, demonstrating that cell death induced by $\mathrm{TNF} \alpha$ is only a marginal phenomenon in our assay.

The possibility that integrins are involved in the adhesion of RA SF to COMP was explored. In accordance with reports by others, ${ }^{12}$ our results indicated that an interaction between COMP and CD51 is essential for the adhesion process of RA SF. This suggests a role for this system in cell attachment to the hyaline cartilage. CD51 also mediates, for example, human chondrocyte adhesion to cartilage. ${ }^{17}$ The constitutive expression of CD51 is about two times higher in RA. Of course, RA SF also expressed other $\alpha$ integrin subunits, for example $\alpha 6,{ }^{18}$ and it can be speculated that integrin subunits are differently regulated under inflammatory conditions.

An explanation was found for the TNF $\alpha$ induced decrease of cell adhesion to various ECM components. FACS was used to measure the expression of integrin subunits on SF cell membranes, before and after a 30 minute incubation with $\mathrm{TNF} \alpha$ - that is, corresponding to the treatment before the attachment assay. In both OA SF and RA SF, the short incubation with TNF $\alpha$ modestly increased the expression of CD29 on the cell surface. Similarly, CD51 was increased in RA $\mathrm{SF}$. In contrast, CD61 is down regulated in both RA SF and $\mathrm{OA} S \mathrm{SF}$, suggesting that it is the rate limiting factor in the adhesion to COMP after pretreatment with TNF $\alpha$. CD61 might not be the only integrin that is down regulated by $\mathrm{TNF} \alpha$, because this also is seen for $\alpha 6$ and $\beta 4 .^{19}$

The $\beta 3$ integrin subunit (CD61) forms a complex with the $\alpha \mathrm{V}$ subunit (CD51) to form the vitronectin receptor. Our experimental data suggest that the $\alpha \mathrm{V}$ and $\beta 3$ integrins, independently of one another, or as a complex, are major switches regulating the attachment capability of these cells. The $\alpha \mathrm{V} \beta 3$ integrin complex has been reported by others to bind to thrombospondin-1 (TSP-1), ${ }^{20}$ a molecule with high amino acid homology to COMP (also known as thrombospondin-5). In fibroblasts, an autocrine loop of the integrin $\alpha \mathrm{V} \beta 3 / \mathrm{CD} 47$ receptor complex and TSP-1 is identified as the molecular coupling device between mechanical loading and apoptosis. Recently, it has been proposed that the CD47/TSP-1 interaction is a key component of an SF/T cell regulatory circuit that perpetuates the inflammatory process in the RA joint. ${ }^{21}$ TSP-1 can increase the production of growth factors ${ }^{22}$ and this can be partially blocked by anti- $\alpha \mathrm{V} \beta 3$ antibodies, indicating that it may be mediated, in part, by TSP-1 binding to those integrins.

COMP was found to stimulate the intracellular accumulation of galectin-3 in RA SF. Increased levels of galectin-3 are detected in the RA synovial fluid ${ }^{4}$; however, in vitro, galectin-3 was not released from RA SF after attachment to COMP. Thus, it is attractive to speculate on the possibility of a lectin independent intracellular role ${ }^{2}$ upon attachment, but this has to be verified experimentally. In RA, galectin-3 was found throughout the synovial tissue and in certain patients prominently at sites of joint destruction. ${ }^{4}$ This clearly suggests an in vivo induction by multiple factors, including attachment.

TNF $\alpha$ reduced the expression of galectin-3 within 18 hours in both "floating" OA SF and RA SF. The effect of TNF $\alpha$ is dependent on dose and time. In RA, it can show high interindividual variations; a modest and transient accumulation (instead of a decrease) of intracellular galectin-3 can occur, while galectin-3 gene translation and protein secretion remain unchanged. ${ }^{4}$ Not only the stage of the disease but also the localisation of the biopsy and the "imprinting" of former treatments can bias the results. Taken together, our data suggested that the obvious induction of galectin-3 in situ is not the result of proinflammatory cytokines, but rather appears after the adhesion to certain ECM components.

Three hypotheses about the origin of adhesive RA synovial cells can be considered: (a) cells of the synovial lining come directly into contact with cartilage and bone and invade these structures; $(b)$ collagenase-producing synovial cells detach from the tissue, reach the synovial fluid and attach to cartilage and bone; or $(c)$ precursor cells originate from, for example, the bone marrow, and differentiate into highly destructive fibroblast-like cells in the joint cavity. Indeed, a subpopulation of activated mononuclear cells floating in the RA synovial fluid can differentiate into fibroblast-like cells and they have the potential to destroy human cartilage. ${ }^{23}$ $\mathrm{TNF} \alpha$ inhibits the adhesion process of floating cells by reducing the expression of CD61, but does not reverse the cellular adhesion to COMP once it has taken place. After attachment, the cells can either destroy the ECM or proliferate. ${ }^{24}$ Based on our data, it would be predicted that in a florid RA, TNF $\alpha$ decreases the adhesion of SF to cartilage; alternatively, other receptor-matrix interactions might exist during this condition allowing the attachment of SF and triggering the destruction. However, inflammation and destruction are dissociated phenomena'; possibly, SF become attached before the first clinical signs of inflammation and/or during clinically more "quiet" phases. It is important to note that one should be very cautious when transferring the in vitro data from samples of late stage disease to the in situ situation.

The proliferation of SF in response to growth factors requires a second signal generated after adhesion to an ECM component. ${ }^{25}$ Possibly, the adhesion process protects the cells from TNF $\alpha$ induced apoptosis occurring locally in the presence of high concentrations of this cytokine. Because intracellularly, galectin-3 is an anti-apoptotic molecule, ${ }^{26}$ it is tempting to speculate that its up regulation after the adhesion of RA SF to cartilage components might induce a transient resistance to apoptosis at sites of joint destruction. Thus, CD51 $1^{27}$ and possibly CD61, as well as galectin-3, could represent promising therapeutic targets for the treatment of RA.

\section{Authors' affiliations}

M Neidhart, R von Knoch, A Jüngel, B A Michel, R E Gay, S Gay, Centre for Experimental Rheumatology, University Hospital, CH-8091 Zurich, Switzerland

F Zaucke, Centre for Biochemistry, Medical Faculty, University of Cologne, D-50931 Cologne, Germany

\section{REFERENCES}

1 Gay S, Kuchen S, Gay RE, Neidhart M. Cartilage destruction in rheumatoid arthritis. Ann Rheum Dis 2002;61(suppl II):ii87.

2 Hsu DK, Liu FT. Regulation of cellular homeostasis by galectins. Glycoconj J 2004; 19:507-15.

3 Almkvist J, Karlsson A. Galectins as inflammatory mediators. Glycoconi J 2004; 19:575-81.

4 Ohshima S, Kuchen S, Seemayer CA, Kyburz D, Hirth A, Klinzing S, et al. Galectin-3 and its binding protein in rheumatoid arthritis. Arthritis Rheum 2003;48:2788-95.

5 Kadrofske MM, Openo KP, Wang JL. The human LGALS3 (galectin-3) gene: determination of the gene structure and functional characterization of the promoter. Arch Biochem Biophys 1998;349:7-20.

6 Ishikawa H, Hirata S, Andoh Y, Kubo H, Nakagawa N, Nishibayashi Y, et al. An immunohistochemical and immunoelectron microscopic study of adhesion molecules in synovial pannus formation in rheumatoid arthritis. Rheumatol Int 1996;16:53-60.

7 Hummel KM, Neidhart M, Vilim V, Hauser N, Aicher WK, Gay RE, et al. Analysis of cartilage oligomeric matrix protein (COMP) in synovial fibroblasts and synovial fluids. BrJ Rheumatol 1998;37:721-8.

8 Neidhart M, Hauser N, Paulsson M, DiCesare PE, Michel BA, Häuselmann HJ. Small fragments of cartilage oligomeric matrix protein in synovial fluid and 
serum as markers for cartilage degradation. $\mathrm{Br} J$ Rheumatol 1997;36:1151-60.

9 Mansson B, Gulfe A, Geborek P, Heinegard D, Saxne T. Release of cartilage and bone macromolecules into synovial fluid: differences between psoriatic arthritis and rheumatoid arthritis. Ann Rheum Dis 2001;60:27-31.

10 Kuhne SA, Neidhart M, Everson MP, Hantzschel H, Fine PR, Gay S, et al. Persistent high serum levels of cartilage oligomeric matrix protein in a subgroup of patients with traumatic knee injury. Rheumatol Int 1998;18:21-5.

11 Carlsen S, Hansson AS, Olsson H, Heinegard D, Holmdahl R. Cartilage oligomeric matrix protein (COMP)-induced arthritis in rats. Clin Exp Immunol 1998; 114:477-84

12 Rinaldi N, Schwarz-Eywill M, Weis D, Leppelmann-Jansen P, Lukoschek M, Keilholz $U$, et al. Increased expression of integrins on fibroblast-like synoviocytes from rheumatoid arthritis in vitro correlates with enhanced binding to extracellular matrix proteins. Ann Rheum Dis 1997;56:45-51.

13 Wang AZ, Wang JC, Fisher GW, Diamond HS. Interleukin-1 $\beta$-stimulated invasion of articular cartilage by rheumatoid synovial fibroblasts is inhibited by antibodies to specific integrin receptors and by collagenase inhibitors. Arthritis Rheum 1997;40:1298-307.

14 Arnett FC, Edworthy SM, Bloch DA, McShane DJ, Fries JF, Cooper NS, et al. The American Rheumatism Association 1987 revised criteria for the classification of rheumatoid arthritis. Arthritis Rheum 1988;31:315-24.

15 Altman R, Asch E, Bloch D, Bole G, Borenstein D, Brandt K, et al. Development of criteria for the classification and reporting of osteoarthritis. Classification of osteoarthritis of the knee. Arthritis Rheum 1986;29:1039-49.

16 Akiyama SK. Functional analysis of cell adhesion: quantification of cell-matrix attachment. In: Adams JC, ed. Methods in cell-matrix adhesion. London: Academic Press, 2002:281-96.

17 Kurtis MS, Schmidt TA, Bugbee WD, Loeser RF, Sah RL. Integrin-mediated adhesion of human articular chondrocytes to cartilage. Arthritis Rheum 2003;48:110-18.
18 Pirila L, Aho H, Roivainen A, Konttinen YT, Pelliniemi U, Heino J. Identification of alphabbetal integrin positive cells in synovial lining layer as type B synoviocytes. J Rheumatol 2001;28:478-84.

19 Stadlmann S, Raffeiner R, Amberger A, Margreiter R, Zeimet AG Abendstein $B$, et al. Disruption of the integrity of human peritoneal mesothelium by interleukin-1 beta and tumor necrosis factor-alpha. Virchows Arch 2003;443:678-85

20 Graf R, Freyberg M, Kaiser D, Friedl P. Mechanosensitive induction of apoptosis in fibroblasts is regulated by thrombospondin-1 and integrin associated protein (CD47). Apoptosis 2002;7:493-8.

21 Vallejo AN, Yang H, Klimiuk PA, Weyand CM, Goronzy JJ. Synoviocytemediated expansion of inflammatory T cells in rheumatoid synovitis is dependent on CD47-thrombospondin 1 interaction. J Immunol 2003;171:1732-40.

22 Mousa SA, Lorelli W, Campochiaro PA. Role of hypoxia and extracellular matrix-integrin binding in the modulation of angiogenic growth factors secretion by retinal pigmented epithelial cells. J Cell Biochem 1999:17:135-43.

23 Neidhart M, Seemayer CA, Hummel K, Michel BA Gay RE, Gay S. Functional characterization of adherent synovial fluid cells in rheumatoid arthritis: destructive potential in vitro and in vivo. Arthritis Rheum 2003;48:1873-80.

24 Seemayer CA, Kuchen S, Künzler P, Rihoskova V, Rethage J, Aicher WK et al. Cartilage destruction mediated by synovial fibroblasts does not depend on proliferation in rheumatoid arthritis. Am J Pathol 2003;162:1549-57.

25 Sarkissian M, Lafyatis R. Integrin engagement regulates proliferation and collagenase expression of rheumatoid synovial fibroblasts. J Immunol 1999;162:1772-9.

26 Yang RY, Liu FT. Galectins in cell growth and apoptosis. Cell Mol Life Sci 2003;60:267-76

27 Wilder RL. Integrin $\alpha \mathrm{V} \beta 3$ as a target for treatment of rheumatoid arthritis and related rheumatic diseases. Ann Rheum Dis 2002;61(suppl II):ii96-9. 